\title{
Mangrove sequencing: analysis of zonation in a complete river system
}

\author{
Bunt, J. S., Williams, W. T., Hunter, J. F., Clay, H. J. \\ ${ }^{1}$ 4/6 McDonald Street, Potts Point, N.S.W. 2011, Australia \\ ${ }^{2} 10$ Surrey Street, Hyde Park, Townsville, Queensland 4812, Australia \\ ${ }^{3}$ Department of Mathematics, James Cook University, Townsville, Queensland 4811, Australia \\ ${ }^{4}$ Australian Institute of Marine Science, PMB No.3, Townsville, Queensland 4810, Australia
}

\begin{abstract}
A numeric technique developed by Williams et al. (1991) has been used to investigate and demonstrate the value of the approach for revealing mangrove zonation patterns in a complex data set from the Endeavour River in northeastern Australia. As part of the enquiry, it has been shown that species sequences are not constant along the river and that some clustering is evident with variable levels of affinity between the species within individual clusters. Also, statistical analysis has shown that there is a significant trend, as one moves upriver, for the species to position themselves closer to the water's edge. It appears likely that the procedure adopted may be useful in similar situations in mangroves elsewhere and perhaps in other types of fixed communities where zonation may be present but is not obvious.
\end{abstract}

\section{INTRODUCTION}

Species zonation is a widely recognized and commonly obvious feature of mangrove forests. The extent of the literature on this topic has been noted by Lugo \& Snedaker (1974). Where the zones are monospecific or nearly so, as is sometimes the case, the depiction of sequences from water frontages to the tidal limit is unequivocal. On the other hand, there are many situations, especially where species diversity is high and/or where freshwater influences are strong, where zonation, although present, becomes difficult to characterize objectively. This problem often arises along the northeastern coasts of Australia and their associated riverine estuaries as Bunt \& Williams (1980) have reported and as has been considered by Hutchings \& Saenger (1987). Indeed, the simpler patterns earlier reported for this region by Macnae (1967) are not generally characteristic. Further, even when zonation is quite clear cut, the sequences of species are not always the same from location to location.

Complexities of the kind outlined above and as detailed by Bunt \& Williams (1981) led us to seek a means to detect sequences by computational means. A method proposed by Williams et al. (1991) appears to satisfy requirements. Briefly, any one species, in any one transect, could be associated with a value corre- sponding to the mean relative distance along the transect, the water's edge being taken as zero. It was pointed out that the values so obtained were not independent of the number of sample sites in the transect; a method of standardization was defined which would constrain each mean between 0 and 1 , so making it possible for the species-means from different transects to be compared. Moreover, it was then possible to consider the constrained means as additive, so that they could be consolidated into a set of values for a complete river system.

On that basis, we examine the statistical and other numerical problems as well as the findings which arise in the analysis of such a complete system.

Before doing so, it is appropriate to note how this work differs from that of Pielou (1977). Given a set of contiguous quadrats displaying what appears to be some form of overt zonation, she is concerned to establish a test of statistical significance. Our problem differs in that the scales make it impossible to have either the transects or the sites contiguous. More importantly, we are primarily concerned to establish whether there is any evidence of zonation at all and, if so, whether or not it is invariant. Thus, the present work is essentially exploratory and not sufficiently advanced to establish whether the Pielou techniques might be applicable in study of the mangroves. 


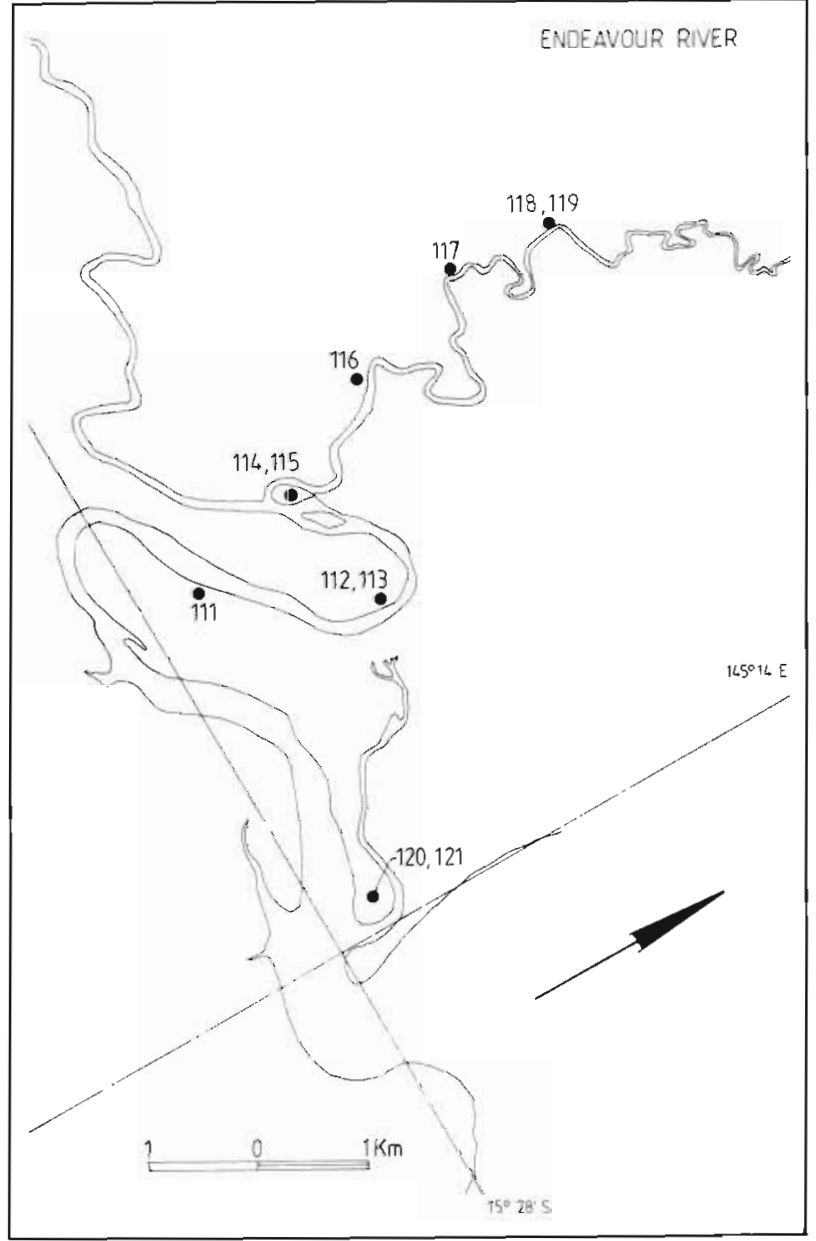

Fig. 1. Endeavour River in northeastern Australia indicating location of study transects

\section{DATA}

The chosen river is the Endeavour, discharging to the sea at $15^{\circ} 28^{\prime} \mathrm{S}$ and $145^{\circ} 14^{\prime} \mathrm{E}$ in NE Australia (Fig. 1). The mean annual rainfall in the area is $1700 \mathrm{~mm}$ with heavy summer incidence. Air temperatures range from a mean minimum (July) of $19.5^{\circ} \mathrm{C}$ to a mean maximum (January) of $31.1^{\circ} \mathrm{C}$.

Eleven transects were completed (Fig. 1 indicates the position of the first site in each transect. Serial numbers are in order of survey). The numbers of sites in Transects 111 to 121 were respectively $7,23,25,8,7,9,12,8$, $5,12,16$ : total 130 ; standardization for the number of sites per transect was obviously essential although the distance between sites along all transects was approximately equal.

The total number of species encountered was 25 , including 2 mangrove associates; these are listed in Table 1. The serial numbers allocated to the species are taken from the major data base with field methodology published by the Australian Institute of Marine Science
Table 1. Species present in Endeavour River transects

\begin{tabular}{|c|c|c|}
\hline $\begin{array}{l}\text { Species } \\
\text { code no. }\end{array}$ & $\begin{array}{l}\text { Frequency } \\
\quad \text { (sites) }\end{array}$ & Name \\
\hline 1 & 26 & Acrostichum speciosum Willd. \\
\hline 2 & 10 & Acanthus ilicifolius L. \\
\hline 3 & 7 & Aegialitis annulata $\mathrm{R} . \mathrm{Br}$. \\
\hline 4 & 15 & $\begin{array}{l}\text { Aegiceras corniculatum (L.) } \\
\text { Blanco }\end{array}$ \\
\hline 5 & 20 & Avicennia sp. \\
\hline 8 & 81 & Bruguiera gymnorrhiza (L.) Lam. \\
\hline 9 & 33 & $\begin{array}{l}\text { B. parviflora (Roxb.) Wight \& Arn } \\
\text { ex Griff. }\end{array}$ \\
\hline 11 & 46 & Ceriops tagalvar. australis $\mathrm{C} . \mathrm{T} W$ \\
\hline 12 & 28 & C. decandra (Roxb.) Ding Hou \\
\hline 13 & 35 & Cynometra iripa Kostel ${ }^{\mathrm{a}}$ \\
\hline 14 & 60 & Excoecaria agallocha L. \\
\hline 15 & 57 & Heritiera littoralis Ait. \\
\hline 20 & 8 & Osbornia octodonta F. Muell. \\
\hline 21 & 30 & Rhizophora apiculata Bl. \\
\hline 22 & 1 & R. lamarkii Montr. \\
\hline 23 & 19 & R. mucronata Lam. \\
\hline 24 & 11 & R. stylosa Griff. \\
\hline 26 & 2 & Sonneratia alba Sm. \\
\hline 27 & 1 & S. caseolaris (L.) Engl. \\
\hline 30 & 47 & Xylocarpus granatum Koenig \\
\hline 31 & 38 & $X$ mekongensis Pierre ${ }^{b}$ \\
\hline 32 & 1 & $\begin{array}{l}\text { Diospyros ferrea var geminata } \\
\text { (R. Br.) Bakh. }\end{array}$ \\
\hline 33 & 5 & Bruguiera sexangula (Lour.) Poir. \\
\hline 34 & 7 & $\begin{array}{l}\text { Hibiscus tiliaceus L. (mangrove } \\
\text { associate) }\end{array}$ \\
\hline 35 & 4 & $\begin{array}{l}\text { Melaleuca spp. (mangrove } \\
\text { associate) }\end{array}$ \\
\hline
\end{tabular}

(Bunt 1982) and have been retained for convenience in reference to other published work from the same source. The frequencies given represent the number of sites (ex 130) in which each species was encountered.

\section{ANALYSIS I: TABLE OF MEANS}

The complete 2-way table of standardized speciesin-transect means is given in Table 2 . The row- and column-means of such entries as exist have then been calculated, and are included in the Table along with their standard deviations. These will represent speciesand transect-means taken over the whole river system. The importance of this table is sufficiently obvious; the computer program outlined in Williams et al. (1991) has therefore been extended so that, if the computer is informed that a complete river system is under examination, it will automatically compute and print out this table. Three aspects of the display require further investigation 
Table 2. Two-way table of standarized means (with means of rows and columns)

\begin{tabular}{|c|c|c|c|c|c|c|c|c|c|c|c|c|c|}
\hline \multirow{2}{*}{$\begin{array}{l}\text { Species } \\
\text { codes }\end{array}$} & \multicolumn{11}{|c|}{ Transect numbers } & \multirow{2}{*}{$\begin{array}{l}\text { Row } \\
\text { means }\end{array}$} & \multirow[t]{2}{*}{$\mathrm{SD}$} \\
\hline & 111 & 112 & 113 & 114 & 115 & 116 & 117 & 118 & 119 & 120 & 121 & & \\
\hline 1 & 0.67 & 0.67 & 0.67 & 0.64 & 0.58 & 0.50 & - & - & - & - & - & 0.62 & 0.17 \\
\hline 2 & - & 0.82 & 0.82 & - & - & - & - & - & - & - & - & 0.82 & 0.09 \\
\hline 3 & - & - & - & - & - & - & - & - & - & 0.91 & 0.57 & 0.74 & 0.19 \\
\hline 4 & 0.16 & 0.23 & 0.00 & 0.21 & 0.22 & 0.33 & - & - & - & - & 0.07 & 0.15 & 0.12 \\
\hline 5 & 0.42 & 0.61 & - & - & - & - & - & - & - & 0.91 & 0.65 & 0.65 & 0.26 \\
\hline 8 & 0.58 & 0.50 & 0.52 & 0.71 & 0.50 & 0.50 & 0.36 & - & 0.13 & 0.50 & 0.38 & 0.47 & 0.21 \\
\hline 9 & 0.83 & 0.16 & 0.20 & 0.43 & 0.50 & 0.25 & 0.55 & - & 0.00 & - & - & 0.37 & 0.15 \\
\hline 11 & 0.67 & 0.54 & 0.50 & - & - & 0.56 & - & - & - & 0.70 & 0.67 & 0.61 & 0.20 \\
\hline 12 & 0.75 & 0.51 & 0.54 & - & - & - & - & - & - & - & - & 0.60 & 0.23 \\
\hline 13 & - & 0.93 & 0.80 & 0.86 & 0.50 & 0.59 & 0.53 & 0.47 & 0.50 & - & - & 0.65 & 0.18 \\
\hline 14 & 0.67 & 0.72 & 0.74 & 0.71 & 0.67 & 0.56 & 0.50 & 0.60 & 0.42 & - & 0.93 & 0.65 & 0.21 \\
\hline 15 & 0.67 & 0.89 & 0.79 & 0.71 & 0.67 & 0.65 & 0.50 & 0.50 & 0.50 & - & - & 0.65 & 0.21 \\
\hline 20 & - & - & - & - & - & - & - & - & - & 1.00 & 0.63 & 0.81 & 0.19 \\
\hline 21 & - & 0.23 & 0.20 & - & - & - & - & - & - & 0.59 & 0.41 & 0.36 & 0.17 \\
\hline 22 & - & - & 0.04 & - & - & - & - & - & - & - & - & 0.04 & 0.00 \\
\hline 23 & 0.17 & 0.07 & 0.04 & 0.14 & 0.37 & 0.46 & 0.00 & - & - & - & - & 0.18 & 0.14 \\
\hline 24 & - & - & - & - & - & - & - & - & - & 0.14 & 0.30 & 0.22 & 0.19 \\
\hline 26 & - & - & - & - & - & - & 0.05 & - & - & - & - & 0.05 & 0.00 \\
\hline 27 & - & - & - & - & - & - & - & 0.00 & - & - & - & 0.00 & 0.00 \\
\hline 30 & - & 0.40 & 0.35 & 0.64 & 0.50 & 0.56 & 0.51 & - & 0.25 & - & 0.93 & 0.52 & 0.20 \\
\hline 31 & 0.61 & 0.52 & 0.39 & - & - & - & - & - & - & - & - & 0.50 & 0.26 \\
\hline 32 & - & - & - & - & - & - & - & 0.60 & - & - & - & 0.60 & 0.00 \\
\hline 33 & - & - & - & - & - & - & 0.00 & 0.20 & 0.00 & - & - & 0.07 & 0.05 \\
\hline 34 & - & - & - & - & - & - & 0.68 & 0.30 & 0.50 & - & - & 0.49 & 0.17 \\
\hline 35 & - & - & - & - & - & - & 0.91 & - & 0.50 & - & - & 0.71 & 0.10 \\
\hline Column means & 0.56 & 0.52 & 0.44 & 0.56 & 0.50 & 0.50 & 0.42 & 0.38 & 0.31 & 0.68 & 0.55 & & \\
\hline
\end{tabular}

(1) Analysis of variance. Even a cursory inspection of the Table suggests that there is considerably greater variation between species than there is between transects. However, it is desirable to quantify this distinction and to obtain an estimate of the species-transect interaction. Of the 275 possible entries in the Table, only 113 exist; the system is therefore, at least potentially, non-orthogonal and an iterative solution is unavoidable.

The method we have used was originally due to $\mathrm{R}$. A. Fisher, but we have used the procedure detailed in Searle (1971) p. 261. The analysis proceeds in 2 stages. An appropriate model having been defined, the species are first fitted; the model is then adjusted for the information associated with the species, and the transects then fitted. From the sum of the 2 sets of resulting sums of squares we can, by subtraction from the total sum of squares, obtain the interaction. The whole process is then repeated, but with the transects fitted first. The resulting complete analysis is given in Table 3 , from which we can draw 3 conclusions. First, the expected relative importance of species and transects is immediately clear; second, the change in order of fitting has had only negligible results in the individual sum of squares, and their sum remains constant, so that the system, despite the large number of missing values, is substantially orthogonal; third, we note that the interaction sum of squares represents no less than $20.6 \%$ of the total; we consider the interpretation of the interaction later.

(2) Species-means configuration. If the row-means of Table 2 are sorted into ascending order and plotted by rank, we obtain Fig. 2A which has a number of interesting features. It will be noted at once that the distribution of species is not uniform but includes some 7 clusters which vary both in their degree of separation and in their degree of internal affinities. The fact that these patterns are obscure or undetectable in the field or in the original data set is reflected by the generally large standard deviations shown for the species-means. These, in turn, directly reflect the ranges of the various species along transects.

With respect to the details of the whole river sequence, it will be seen that the underlying zonation, notwithstanding the complexity, has some compatibility with the much simpler patterns described earlier in northeastern Australia by Macnae (1967). This is true to the extent that typically frontal species are followed by Rhizophora spp.; Bruguiera spp.; Ceriops spp. and finally landward Avicennia sp. [note that the latter is bimodal as defined by Williams et al. (1991)]. However, the species generally considered to have more landward affinities are less confined than in the Macnae (1967) schema and, where it occurs, Bruguiera sexan- 
Table 3. Analysis of variance of data from Table 2. Numberical entries are sums of squares

Case A: Species fitted first

$\begin{array}{ll}\text { Species } & 4.7135 \\ \text { Transects | Species } & 1.0275 \\ \text { Interaction | Transects, Species } & 1.4874 \\ \text { Total } & 7.2284 \\ & \\ \text { Case B: Transects fitted first } & \\ \text { Transects } & 0.8762 \\ \text { Species I Transects } & 4.8648 \\ \text { Interaction I Species, Transects } & 1.4874 \\ \text { Total } & 7.2284 \\ \end{array}$

gula has frontal affinities (at least in this river). In general, there is a clearer indication of the relative positions of particular species than in the Macnae (1967) treatment. Note, for example, the separation of the means for the 4 species of Rhizophora and also of Bruguiera parviflora and B. gymnorrhiza.

While the whole river plot in Fig. $1 \mathrm{~A}$ is instructive, it should not be overlooked that some species are limited in their distribution along the river. For example,
Rhizophora stylosa is restricted to the lower reaches and species such as Sonneratia caseolaris are confined to the upstream tidal limits. Others, such as Cynometra iripa and Rhizophora mucronata, are also limited, although to a lesser extent. Under those circumstances, rather more detailed inspection of the data is warranted and this has been done in Fig. $1 \mathrm{~B}$ to $\mathrm{E}$ for transects in the lower river, the lower and upper mid sections and the uppermost tidal reaches respectively. Only speciesmeans are shown. It will be observed that clustering tends to become more apparent as one proceeds upstream. Further, and of particular interest, it will be seen that, while there is some consistency in the sequences, many species change their relative positions, commonly through rather ordered changes in their mean values, and that, as a consequence, the composition and internal affinities of the clusters change as well. The data set is not sufficiently large to permit statistical analysis. Nonetheless, experience of conditions in the field suggests that the trends reflect particular responses of the various species to a complex of environmental controls among which the nature and extent of tidal inundation and salinity level must be influential. Varied environmental requirements certainly explain why some species are limited in distribu-

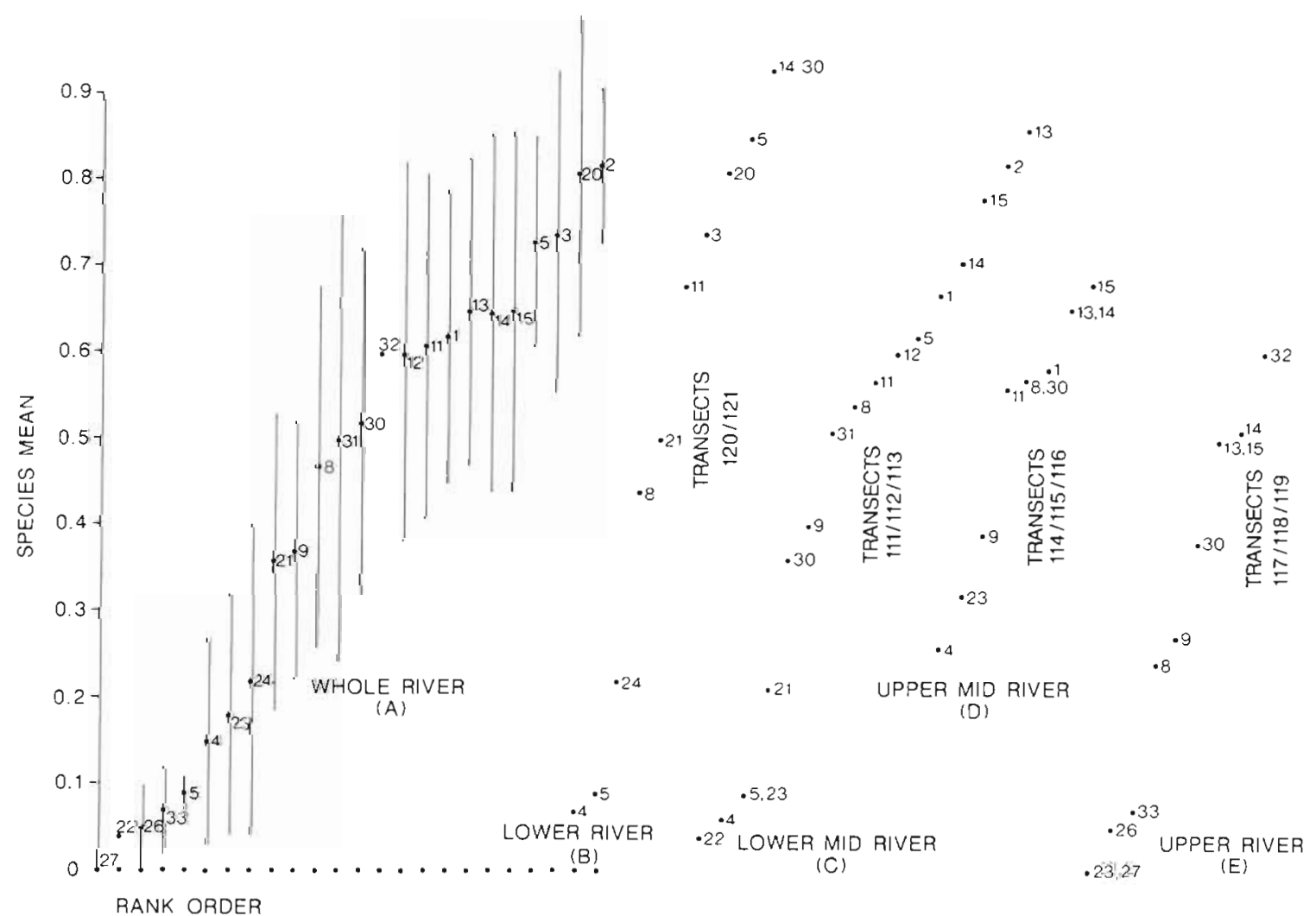

Fig. 2. (A) Whole river plot of species means (with standard deviations) vs rank order in sequence landward from the water's edge. (B to E). Plots as for (A) (without standard deviations marked) but of data for the lower river (B), lower mid river (C), upper mid river (D) and upper river (E) respectively. The numbers on each plot are code numbers for species listed in Table 1 
tion along the river and could equally underlie the observation that sequencing within transects does not remain constant as distance increases from the mouth. The display of underlying patterns such as these should be useful in developing and testing hypotheses concerning likely environmental controls. In that regard, trends in the standard deviations of a number of the species transect-means (reflecting ranges along transects) also warrant attention. In C. iripa, Excoecaria agallocha and Heritiera littoralis, for example, it was found that standard deviations rose to maxima towards the upper tidal limits i.e. $0.08 / 0.15 / 0.28 ; 0.00 / 0.15 / 0.24 /$ $0.31 ; 0.07 / 0.23 / 0.35$ respectively. On the other hand, species such as Aegiceras corniculatum, Bruguiera gymnorrhiza and $R$. mucronata achieved maximal standard deviations in upper mid river while the maximum for Ceriops tagal was downstream. Locations of maxima suggest most favoured locations.

(3) Interaction. In Fig. 3 the transect-means have been plotted against the distance in $\mathrm{km}$ from the river mouth to the beginning of each transect. A linear regression has been drawn in representing the equation:

$$
10 y=6.517-0.147 x
$$

Analysis of variance shows that the line is comfortably significant at the $\mathrm{p}=0.05$ level. The relationship indicates that, as one moves upriver, the mangrove species in general tend to position themselves closer to the water's edge. Based on experience in the field, the

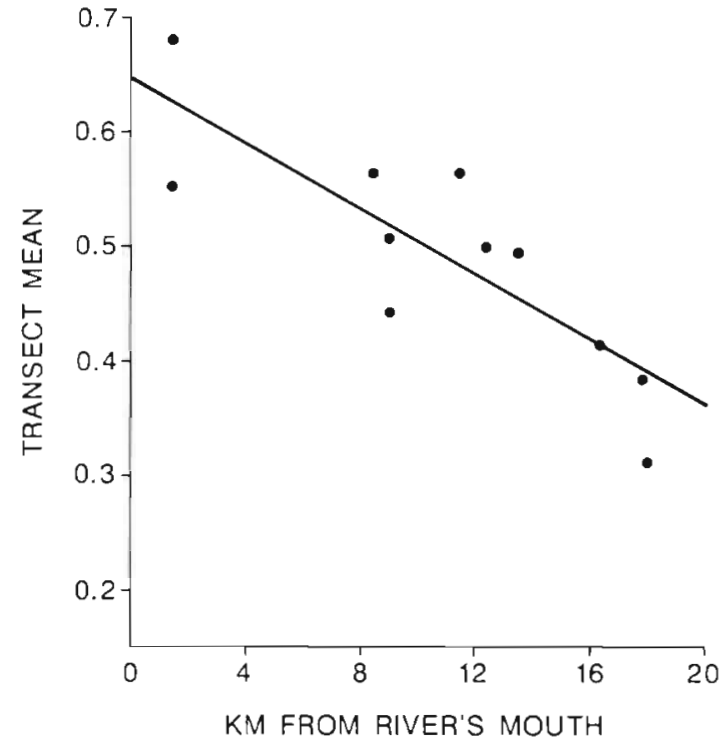

Fig. 3. Regression of transect means (see text) vs distance of transects upstream from river mouth

result is not unexpected. Nonetheless, the underlying causes may be complex and, in any case, are beyond the scope and purpose of this presentation which is concerned principally in demonstrating the utility of the analysis. It is worth noting that something of the overall trend is evident also in Fig. 1B to E.

Table 4. Species co-occurrence table. Data in body of table are frequencies of co-occurrence

\begin{tabular}{|c|c|c|c|c|c|c|c|c|c|c|c|c|c|c|c|c|c|c|c|c|c|c|c|}
\hline \multirow{2}{*}{$\begin{array}{l}\text { Species } \\
\text { code }\end{array}$} & \multicolumn{23}{|c|}{ Species code } \\
\hline & 1 & 2 & 3 & 4 & 5 & 8 & 9 & 11 & 12 & 13 & 14 & 15 & 20 & 21 & 22 & 23 & 24 & 26 & 27 & 30 & 31 & 32 & 33 \\
\hline 1 & 0 & 4 & 0 & 5 & 1 & 24 & 12 & 9 & 5 & 10 & 23 & 20 & 0 & 0 & 0 & 7 & 0 & 0 & 0 & 20 & 4 & 0 & 0 \\
\hline 2 & 4 & 0 & 0 & 0 & 0 & 9 & 0 & 2 & 4 & 8 & 10 & 10 & 0 & 0 & 0 & 0 & 0 & 0 & 0 & 1 & 4 & 0 & 0 \\
\hline 3 & 0 & 0 & 0 & 1 & 6 & 1 & 0 & 5 & 0 & 0 & 1 & 0 & 6 & 3 & 0 & 0 & 3 & 0 & 0 & 1 & 0 & 0 & 0 \\
\hline 4 & 5 & 0 & 1 & 0 & 4 & 6 & 5 & 2 & 0 & 1 & 3 & 2 & 1 & 1 & 0 & 12 & 1 & 0 & 0 & 5 & 1 & 0 & 0 \\
\hline 5 & 1 & 0 & 6 & 4 & 0 & 6 & 2 & 13 & 4 & 1 & 6 & 3 & 7 & 7 & 0 & 4 & 4 & 0 & 0 & 2 & 5 & 0 & 0 \\
\hline 8 & 24 & 9 & 1 & 6 & 6 & 0 & 25 & 36 & 25 & 21 & 43 & 36 & 1 & 22 & 0 & 9 & 3 & 1 & 0 & 41 & 33 & 0 & 1 \\
\hline 9 & 12 & 0 & 0 & 5 & 2 & 25 & 0 & 6 & 5 & 9 & 18 & 17 & 0 & 6 & 1 & 9 & 0 & 0 & 0 & 23 & 11 & 0 & 1 \\
\hline 11 & 9 & 2 & 5 & 2 & 13 & 36 & 6 & 0 & 20 & 3 & 21 & 10 & 6 & 15 & 0 & 2 & 3 & 0 & 0 & 16 & 22 & 0 & 0 \\
\hline 12 & 5 & 4 & 0 & 0 & 4 & 25 & 5 & 20 & 0 & 3 & 15 & 7 & 0 & 6 & 0 & 0 & 0 & 0 & 0 & 12 & 24 & 0 & 0 \\
\hline 13 & 10 & 8 & 0 & 1 & 1 & 21 & 9 & 3 & 3 & 0 & 29 & 35 & 0 & 0 & 0 & 1 & 0 & 0 & 0 & 15 & 4 & 0 & 3 \\
\hline 14 & 23 & 10 & 1 & 3 & 6 & 43 & 18 & 21 & 15 & 29 & 0 & 48 & 1 & 0 & 0 & 6 & 0 & 1 & 0 & 29 & 14 & 0 & 4 \\
\hline 15 & 20 & 10 & 0 & 2 & 3 & 36 & 17 & 10 & 7 & 35 & 48 & 0 & 0 & 0 & 0 & 5 & 0 & 2 & 1 & 26 & 8 & 1 & 5 \\
\hline 20 & 0 & 0 & 6 & 1 & 7 & 1 & 0 & 6 & 0 & 0 & 1 & 0 & 0 & 4 & 0 & 0 & 3 & 0 & 0 & 1 & 0 & 0 & 0 \\
\hline 21 & 0 & 0 & 3 & 1 & 7 & 22 & 6 & 15 & 6 & 0 & 0 & 0 & 4 & 0 & 0 & 0 & 7 & 0 & 0 & 7 & 9 & 0 & 0 \\
\hline 22 & 0 & 0 & 0 & 0 & 0 & 0 & 1 & 0 & 0 & 0 & 0 & 0 & 0 & 0 & 0 & 0 & 0 & 0 & 0 & 1 & 1 & 0 & 0 \\
\hline 23 & 7 & 0 & 0 & 12 & 4 & 9 & 9 & 2 & 0 & 1 & 6 & 5 & 0 & 0 & 0 & 0 & 0 & 1 & 0 & 9 & 3 & 0 & 1 \\
\hline 24 & 0 & 0 & 3 & 1 & 4 & 3 & 0 & 3 & 0 & 0 & 0 & 0 & 3 & 7 & 0 & 0 & 0 & 0 & 0 & 0 & 0 & 0 & 0 \\
\hline 26 & 0 & 0 & 0 & 0 & 0 & 1 & 0 & 0 & 0 & 0 & 1 & 2 & 0 & 0 & 0 & 1 & 0 & 0 & 0 & 1 & 0 & 0 & 1 \\
\hline 27 & 0 & 0 & 0 & 0 & 0 & 0 & 0 & 0 & 0 & 0 & 0 & 1 & 0 & 0 & 0 & 0 & 0 & 0 & 0 & 0 & 0 & 0 & 1 \\
\hline 30 & 20 & 1 & 1 & 5 & 2 & 41 & 23 & 16 & 12 & 15 & 29 & 26 & 1 & 7 & 1 & 9 & 0 & 1 & 0 & 0 & 16 & 0 & 0 \\
\hline 31 & 4 & 4 & 0 & 1 & 5 & 33 & 11 & 22 & 24 & 4 & 14 & 8 & 0 & 9 & 1 & 3 & 0 & 0 & 0 & 16 & 0 & 0 & 0 \\
\hline 32 & 0 & 0 & 0 & 0 & 0 & 0 & 0 & 0 & 0 & 0 & 0 & 1 & 0 & 0 & 0 & 0 & 0 & 0 & 0 & 0 & 0 & 0 & 0 \\
\hline 33 & 0 & 0 & 0 & 0 & 0 & 1 & 1 & 0 & 0 & 3 & 4 & 5 & 0 & 0 & 0 & 1 & 0 & 1 & 1 & 0 & 0 & 0 & 0 \\
\hline
\end{tabular}




\section{ANALYSIS II: CO-OCCURRENCE MATRIX}

The co-occurrence matrix for the entire river is given in Table $4 ;$ in this table, the entry for each pair of species represents the number of sites (ex 130) in which those 2 species occur together. The weakness of the cooccurrence matrix is its sensitivity to frequency. To take an extreme example, a species which is ubiquitous, or nearly so, must have positive entries with most, or even all, of the other species in the system. In contrast, 2 rare species which are ecologically similar, in that both occur only at the water's edge, but which do not happen to have been encountered in the same transect, cannot appear grouped in the matrix.

Nevertheless, we considered it desirable to examine whether the matrix can provide a method of species grouping. In order to reduce extreme values, the entries were subjected to a conventional $\ln (1+x)$ transformation; since the matrix as it stands is a similarity' matrix, and modern classificatory programs all demand a dissimilarity matrix, the values were subtracted from a suitable maximum possible value, in this case 4.0 . The resulting matrix was classified by the usual 'incremental' or 'error' sum-of-squares fusion strategy. The results were disappointing, but not unexpected: the resulting groups had little ecological meaning, but instead grouped together species of roughly comparable frequency.

It does not follow that the co-occurrence matrix is worthless; its potential value lies in the possibility of enquiring, of any one species, with which other species it is likely to be associated. Equally, one can extract from the matrix information on those species of highest frequency in any particular river and the extent of their principal associations.

\section{CONCLUSIONS}

The analysis proposed by Williams et al. (1991) and applied here to data on mangrove distributions in a particular river, the Endeavour, in northeastern Australia, appears to us to have several useful features:

This article was submitted to the editor
(1) it permits the identification of sequencing patterns (zonation) in otherwise complex data sets;

(2) it demonstrates in an objective fashion that species sequences can vary in character with indications of an underlying order;

(3) consideration of revealed vegetational patterns within particular riverine estuaries or other mangrove environments should facilitate the development of testable hypotheses to establish the nature of still poorly understood environmental controls;

(4) an approach of this kind offers a convenient and effective means of considering and comparing vegetational pattern as it varies from location to location regionally;

(5) a procedure of this kind might prove worthwhile in communities other than mangroves where zonation appears to be occurring but is difficult to characterize.

Acknowledgements. The authors are most grateful to Mrs E. D. Bunt for her assistance in the collection of data in the field. Thanks are also offered to Connell Wagner, Engineers, and to Prof. A. Larkum, University of Sydney, for assistance in the preparation of the figures.

\section{LITERATURE CITED}

Bunt, J. S. (1982). Mangrove transect data from northern Queensland. Australian Institute Marine Science Data Report, Townsville. AIMS-CS-82-1: 1-41

Bunt, J. S., Williams, W. T (1980). Studies in the analysis of data from Australian tidal forests ('mangroves'). Aust. $J$. Ecol. 5: 385-390.

Bunt, J. S., Williams, W T. (1981). Vegetational relationships in the mangroves of tropical Australia. Mar. Ecol. Prog Ser. 4: 349-359

Hutchings, P., Saenger, P. (1987). Ecology of mangroves Queensland Univ. Press

Lugo, A. E., Snedaker, S. C. (1974). The ecology of mangroves. A. Rev. Ecol. Syst. 5: 39-64

Macnae, W. (1987). Zonation within mangroves associated with estuaries in North Queensland. In: Lauff, G. H. (ed.) Estuaries. Publs Am. Ass. Advmt Sci. 83: 432-441

Pielou, E. C. (1977). Mathematical ecology. John Wiley and Sons, New York

Searle, S. R. (1971). Linear models. John Wiley and Sons, New York

Williams, W. T., Bunt, J. S., Clay, H. J. (1991). Yet another method of species sequencing. Mar. Ecol. Prog. Ser. 72: 283-287

Manuscript first received: August 21, 1990

Revised version accepted: February 5, 1991 